\title{
DEMANDAS FEMINISTAS E POSICIONAMENTO DE MARCA: UMA ANÁLISE DA COMUNICAÇÃO DAS EMPRESAS BOMBRIL, RISQUÉ E SKOL
}

\author{
LAURA MÁXIMO TEODORO \\ UNIVERSIDADE FEDERAL DE UBERLÂNDIA \\ UBERLÂNDIA, MINAS GERAIS, BRASIL \\ E-MAIL: LAURAMAXT@GMAIL.COM \\ CHRISTIANE PITANGA SERAFIM DA SILVA \\ UNIVERSIDADE METODISTA DE SÃO PAULO \\ SÃO BERNARDO DO CAMPO, SÃO PAULO, BRASIL \\ E-MAIL: CHRISPITANGA@YAHOO.COM.BR
}

HTTP://DX.DOI.ORG/10.5902/2316882X21541 
DEMANDAS FEMINISTAS E POSICIONAMENTO DE MARCA: UMA ANÁLISE DA COMUNICAÇÃO DAS EMPRESAS BOMBRIL, RISQUÉ E SKOL

Resumo: O presente artigo apresenta uma análise do posicionamento das marcas Bombril, Risqué e Skol diante das demandas feministas atuais. Para tanto, foram analisadas campanhas de comunicação veiculadas por estas empresas no ano de 2015 e a resposta de suas assessorias à repercussão negativa das referidas propagandas. Tomando como base a Análise do Discurso, a pesquisa diagnosticou que as marcas analisadas adotam ideologias sexistas.

Palavras-chave: Publicidade e Propaganda; Assessoria de Imprensa; Comunicação Organizacional; representação feminina.

DEMANDAS FEMINISTAS Y EL POSICIONAMIENTO DE MARCA: UN ANÁLISIS DE LA COMUNICACIÓN DE LAS EMPRESAS BOMBRIL, RISQUÉ Y SKOL

Resumen: Este artúclo se presenta un análisis del posicionamiento de la marca Bombril, Risqué y Skol bajo las actuales demandas feministas. Para ello, se analizaron campañas de comunicación hechas por estas empresas en 2015 y la respuesta de su consejero de prensa el impacto negativo de la publicidad. Con base en el análisis del discurso, la investigación concluye que las marcas analizadas adoptan ideologías sexistas.

Palabras Clave: Publicidad y Propaganda; Asesoria de Prensa; Comunicación Organizativa; representación femenina.Curriculum in higher education: requirements for training in cultural production

FEMINIST DEMANDS AND BRAND POSITIONING: COMMUNICATION ANALYSIS OF THE COMPANIES BOMBRIL, RISQUÉ AND SKOL

Abstract: This article presents an analysis of the brand positioning of Bombril, Risqué and Skol under the current feminist demands. Fot this, were analyzed communication campaigns made by these companies in 2015 and the response of their communications departments to the negative impact of such advertisements. Based on the Discourse Analysis, the survey noted that the analyzed brands adopt sexist ideologies.

Keywords: Advertising and Publicity; Press Office; Corporate Communication; representation of women. 


\section{INTRODUÇÃO}

As inovações tecnológicas iniciadas em meados no século XX e intensificadas no início do terceiro milênio provocaram um excesso de produtos e serviços similares e à disposição do consumidor. A partir dessa ausência de diferenciação tangível entre bens de consumo e marcas, um esforço de personalização e diálogo entre empresas e consumidores tornou-se necessário. Questões como atendimento, preço, qualidade e problemáticas éticas e sociais passaram a ser avaliadas pelo consumidor na hora de adquirir produtos e serviços.

Em função disso, as instituições têm tratado a gestão de marca como ponto estratégico, a fim de buscar um posicionamento de mercado alinhado às demandas sociais da atualidade. Nesse contexto, a Propaganda e a Assessoria de Comunicação, como instrumentos de expressão de uma marca, têm a função de produzir discursos alinhados às demandas do público, observando não somente as mudanças tecnológicas, mas atentas às modificações de perspectiva social.

O feminismo foi um dos movimentos sociais que obteve mais conquistas no último século. Segundo dados do IBGE (2012), a inserção da mulher no mercado de trabalho aumentou consideravelmente nas últimas décadas. No ano de 1970 , apenas $18,5 \%$ da população feminina estava inserida no mercado de trabalho. Já em 2011, esse número aumentou para 45,3\%. Além disso, a legalização do divórcio, popularização da pílula anticoncepcional, o direito das mulheres ao voto e a criação da lei Maria da Penha, que coíbe a violência contra a mulher, foram mudanças sociais representativas para as mulheres, o que alterou o modo como a mulher se identifica e deseja ser identificada na sociedade.

Apesar das conquistas, o desejo de que o gênero feminino seja reconhecido enquanto pertencente ao espaço público e dotado de decisão ainda esbarra em estereótipos que, muitas vezes, são reforçados pela mídia e pelo discurso publicitário.

Considerando essa questão, surgiu a ideia de analisar como grandes marcas têm se posicionado frente às demandas feministas na atualidade. $O$ presente artigo sintetiza resultados obtidos em pesquisa realizada como requisito parcial para obtenção do título de bacharel em Comunicação Social - habilitação em Jornalismo, a partir das análises de campanhas comunicacionais da marca de esmaltes Risqué, dos produtos de limpeza 
Bombril e da cerveja Skol, veiculadas em 2015. O objetivo geral da pesquisa foi analisar se o posicionamento dessas empresas está alinhado às reivindicações feministas surgidas no século XX e intensificadas no século XXI.

Tais marcas foram escolhidas após sofrerem críticas negativas às suas peças publicitárias direcionadas ao público feminino. As propagandas "Homens que amamos", "Toda brasileira é uma diva" e "Esqueci o 'não' em casa”, da Risqué, Bombril e Skol, respectivamente, foram consideradas machistas e sexistas pelo público em redes sociais como o Twitter.

Além de analisar o posicionamento dessas marcas frente às demandas feministas da atualidade, também foi avaliado o comportamento das assessorias de comunicação frente às críticas negativas recebidas por parte do público-alvo. Outros objetivos do estudo foram: estudar as demandas feministas atuais, analisar a representatividade feminina nas peças analisadas e analisar a relação entre marcas e a opinião pública expressa nas redes sociais.

Para o desenvolvimento da pesquisa, além das peças publicitárias, foram analisadas as respostas das assessorias de comunicação às manifestações do público, relacionando os resultados à história e posicionamento de mercado das marcas estudadas. Como método de pesquisa, utilizou-se a Análise do Discurso, pois foram analisadas as construções ideológicas presentes nos textos publicitários e nas notas à imprensa divulgadas pelas empresas.

\section{FEMINISMOS: DO SÉCULO XX À CONTEMPORANEIDADE}

No Brasil, um dos primeiros indícios de articulação do movimento de mulheres foi a luta das sufragistas no início do século XX. Lideradas pela cientista e funcionária pública Bertha Lutz, essas mulheres lutavam pelo direito ao voto e à participação política.

Em 1934, o voto feminino foi adicionado à Constituição brasileira, mas isso não representou mudanças profundas nos "papéis de gênero" da época. Sem menção a modificações efetivas nas relações sociais ou à sexualidade, as feministas focavam suas reivindicações na educação feminina e na conquista do espaço público (SOIBET, 2012).

Apenas entre 1960 e 1980, o feminismo de Segunda Onda (PEDRO, 2012) se ocupou em problematizar assuntos como corpo, sexualidade e violência. Nesse contexto, o movimento de emancipação feminina come- 
çou a tratar de assuntos como direitos econômicos, políticos e educacionais. Grupos de reflexão, periódicos e encontros de mulheres foram organizados como modo de questionamento e aprendizagem. Masturbação, autoestima, contracepção e o prazer feminino eram temas abordados. Nessa época, o trabalho doméstico e os papéis sociais de gênero também foram discutidos. O objetivo era apresentar à mulher novos horizontes em sua vida pessoal e profissional.

Na década de 1990, surge a Terceira Onda feminista (BAILEY apud GOMES; SORJ, 2014). Nesse momento, questões como classe social, etnia, violência, sexualidade e idade são efetivamente associadas às bandeiras do movimento de mulheres. As tendências mais recentes do feminismo reconhecem a pluralidade do gênero feminino e lutam não só por direitos, querem que esses direitos contemplem mulheres de diversas realidades.

Segundo dados do IBGE (2012), em 2011, aproximadamente $44 \%$ das mulheres estavam inseridas no mercado de trabalho formal. A conquista de direitos econômicos e sociais aumentou o contingente de mulheres no mercado de trabalho, mas não alterou determinadas realidades. A mulher trabalhadora teria que conciliar a vida doméstica à rotina de trabalho sem, na maioria dos casos, contar com o parceiro para a divisão das tarefas do lar. Segundo destaca Pedro (2012, p. 251), "mesmo as que recebem tal colaboração (considerada uma 'ajuda'), sentem-se as principais responsáveis pela organização e boa administração do lar”.

Por outro lado, o aumento do número de mulheres economicamente ativas provocou uma relação ainda mais íntima entre o gênero feminino e o consumo. Para Pinsky (2012), elas, que já eram responsáveis pela compra de cosméticos, produtos de higiene, roupas e alimentos de toda família, agora ultrapassam os limites do privado e consomem carros, bebidas alcoólicas, informação e serviços que facilitam a rotina da mulher que trabalha dentro e fora de casa, como lavanderias e alimentos pré-prontos.

Na sociedade contemporânea, o consumo tem papel central. Para Bauman (2008), o estilo de vida adotado por um indivíduo expressa-se nos produtos por ele consumidos. Dos modos de vestir ao restaurante que frequenta, consumir, hoje, significa mostrar ao mundo quais são seus gostos, hábitos e ideologias.

Ao expressar-se por meio do consumo, a mulher, como indivíduo pertencente à sociedade contemporânea, opta por produtos e serviços que possam identificá-la. Uma mulher que se identifica com um estilo de vida 
saudável, consome marcas que têm a saúde como um de seus valores. Mulheres que acreditam na causa ambiental ou na proteção animal têm o consumo de produtos ambientalmente responsáveis como uma forma de expressão. Conforme o mesmo raciocínio, as feministas vão preferir consumir marcas que se relacionam de forma positiva com o movimento e evitarão adquirir produtos e serviços de empresas que veiculam imagens femininas desvalorizadas em suas peças de comunicação.

Pesquisa realizada pela Fundação Perseu Abramo (2011), mostra que o número de brasileiras que se consideram feministas cresceu de $21 \%$, em 2001, para 31\%, em 2010, representando uma grande fatia do mercado consumidor feminino. $O$ contingente aumenta se for considerada a faixa etária mais jovem: 40\% das entrevistadas com de 15 a 17 anos se reconhece como feminista.

A internet, como meio de comunicação popular entre os jovens e ferramenta importante na organização do movimento feminista no Brasil, é essencial na militância e disseminação do pensamento feminista atual. Grupos em redes sociais online, fóruns de discussão, blogs e sites discutem, disseminam e defendem o feminismo atual, propõem a mudança de pensamento na sociedade, questionam os "papéis de gênero" ainda vigentes e representam espaço de discussão crítica a respeito da representação da mulher no discurso publicitário, midiático e jornalístico.

\section{BOMBRIL}

A Bombril é uma marca brasileira que surgiu em 1948 e se destacou no mercado por seu pioneirismo e pelo investimento em marketing e publicidade. A marca é a criadora do Garoto Bombril, um dos maiores sucessos na propaganda brasileira. Interpretadas por Carlos Moreno, as propagandas com o personagem tímido, magro, calvo e carismático permaneceram no ar por mais de 30 anos e foram reconhecidas pelo Guinness Book: o Livro dos Recordes como a série de publicidade mais longa do mundo (DIAS, 2006).

A marca está presente nas redes sociais como Facebook, Instagram, Twitter e no site de compartilhamento de vídeos Youtube. O site oficial da Bombril (www.bombril.com.br) tem informações sobre a história da empresa e projetos sociais, além de divulgar missão, visão e valores da instituição.

Rev.Cad. Comun. Santa Maria, v.21, n.1, art 4, p.92 de 107, jan/abr.2017 
Em seu site oficial, a Bombril define as mulheres que trabalham, cuidam da casa e da família como seu público-alvo. Esse público também está presente em seu slogan: "Bombril, os produtos que evoluíram com as muIheres”. Contudo, a presença de mulheres nas propagandas da Bombril é um fato recente. A tática, adotada pela marca a partir de 2011, tem como objetivo enaltecer o protagonismo social feminino e valorizar a independência da mulher (BOMBRIL, 2015).

\subsection{TODA BRASILEIRA É UMA DIVA}

A propaganda "Toda brasileira é uma diva", da Bombril, tem a cantora Ivete Sangalo e as humoristas Mônica Iozzi e Dani Calabresa como personagens (Figura 1). A campanha foi veiculada nas redes aberta e fechada de televisão a partir do mês de agosto de 2015 e tem anúncios em página única e dupla de revistas, ações de merchandising e divulgação nas mídias sociais como peças de apoio.

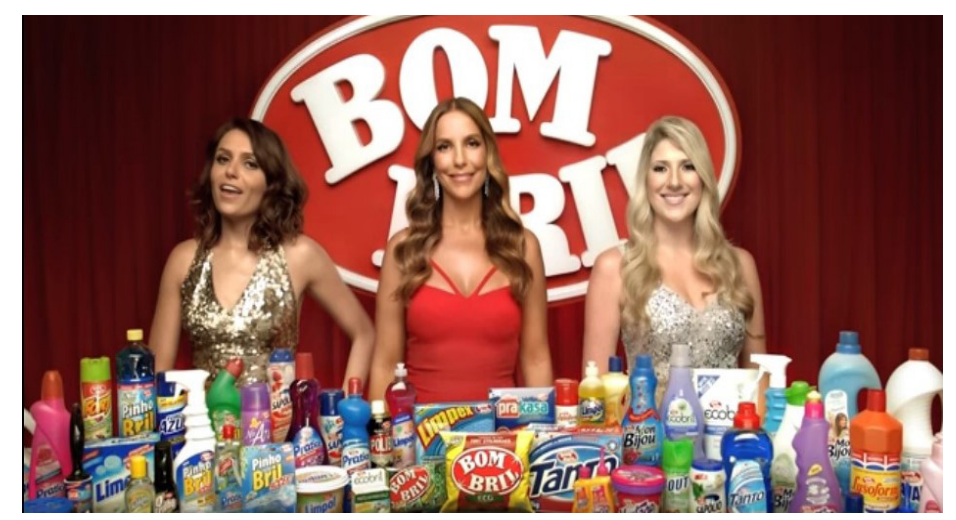

Figura 1 - "Toda brasileira é uma diva"

Fonte: Youtube/Bombril Oficial

Mônica Iozzi: Eu concordo com a Ivete, toda mulher nasceu para brilhar.

Dani Calabresa: E a gente brilha muito!

Ivete Sangalo: Meu amor, a gente arrasa! Arrasa no trabalho, faz sucesso o dia todo e ainda deixa a casa brilhando. É por isso que toda brasileira é uma diva.

Dani Calabresa: Enquanto isso, os homens...

Ivete Sangalo: Ixe. Esses aí não dá! Nem com todos os produtos da Bombril para ajudar na casa.

Mônica lozzi: Não, não dá nem para comparar.

Dani Calabresa: Para comparar dá: toda mulher é uma diva e todo homem é diva-gar.

Ivete Sangalo: Divou! Bombril, os produtos que brilham como toda mulher (BOMBRIL, 2015).

Rev.Cad. Comun. Santa Maria, v.21, n.1, art 4, p.93 de 107, jan/abr.2017 
Fazendo uma leitura flutuante (FREIRE, 2014) é possível observar que a campanha se dedica a enaltecer a marca, tratando-se de uma campanha publicitária de caráter institucional (SANT'ANNA; ROCHA; GARCIA, 2011). Para destacar a Bombril, são utilizadas como apresentadoras celebridades conhecidas pelo estilo irreverente. A propaganda usa o humor como forma de chamar a atenção do espectador (SANT'ANNA; ROCHA; GARCIA, 2011).

O texto da campanha tem início com Mônica lozzi afirmando "Eu concordo com a Ivete, toda mulher nasceu para brilhar". Ao afirmar que concorda com Ivete Sangalo, a humorista se refere ao comercial anteriormente lançado pela Bombril, o primeiro episódio da série "Toda brasileira é uma diva", estrelado pela cantora. Observa-se que a campanha utiliza personagens e temas centrais alongo prazo, como no método chamado Continuos Central Caracter (SANT'ANNA; ROCHA; GARCIA, 2011), com o objetivo de personificar a marca e criar identificação com o público.

A terceira fala do comercial, na voz de Ivete Sangalo, exalta uma muIher multitarefas, que trabalha e cuida do ambiente doméstico: "Arrasa no trabalho, faz sucesso o dia todo e ainda deixa a casa brilhando". A cantora afirma ainda que "É por isso que toda brasileira é uma diva", ou seja, por cumprir tanto as obrigações da vida pública quanto da vida privada, a brasileira é uma diva. Além disso, é possível apontar que ao utilizar a expressão "toda brasileira", a marca parte do pressuposto de que todas as mulheres do país seguem a rotina retratada, se dividindo entre os trabaIhos domésticos e o emprego formal.

O gênero masculino é introduzido na quarta fala do comercial. Com a frase, "Enquanto isso, os homens...", Dani Calabresa inicia a contraposição entre homens e mulheres, seguida pela fala de Ivete Sangalo, "Esses aí não dá! Nem com todos os produtos da Bombril para ajudar na casa”.

A frase indica pela primeira vez de forma explícita o nome da marca Bombril e revela pontos ideológicos interessantes sobre a empresa. Ainda se referindo aos homens, a propaganda usa a expressão "ajudar em casa" para afirmar que homens não desempenham as tarefas domésticas de modo satisfatório. Utilizando como base a Análise do Discurso, surge o questionamento: por que foi utilizada a palavra "ajudar" especificamente? A frase poderia ser substituída por outras como "dividir as tarefas de casa" ou "cumprir as tarefas de casa". Diante disso, surge a questão: qual o posicionamento social da Bombril?

Rev.Cad. Comun. Santa Maria, v.21, n.1, art 4, p.94 de 107, jan/abr.2017 
Em sua definição literal, "ajudar" significa auxiliar ou acudir a alguém, facilitar o trabalho de algum indivíduo, cumprir tarefa que não é originalmente sua. Afirmar que os homens "ajudam em casa", demonstra que o emissor da mensagem, a marca Bombril, pensa as tarefas domésticas como responsabilidade da mulher. O homem que participa da execução desses afazeres não está exercendo uma obrigação, está auxiliando o gênero feminino. Essa formação discursiva revela uma posição ideológica sexista adotada pela marca Bombril.

Baseada nas afirmações anteriores, Dani Calabresa compara os gêneros feminino e masculino afirmando que "toda mulher é uma diva e todo homem é diva-gar". Nessa parte da propaganda é feito um trocadilho entre a palavra-chave da propaganda, "diva”, e o termo "devagar", insinuando que os homens seriam lentos e pouco habilidosos nas tarefas domésticas. O trocadilho continua quando a cantora Ivete Sangalo responde à afirmação de Dani: "Divou”.

O anúncio é finalizado com o slogan da empresa: "Bombril, os produtos que brilham como toda mulher", que repete o nome da marca, o público-alvo da campanha e o conceito da empresa: o brilho.

\section{2 "VALORIZAR O PROTAGONISMO FEMININO"}

A propaganda “Toda brasileira é uma diva” sofreu críticas de feministas e por parte de homens que consideraram a campanha ofensiva à figura masculina. Em texto enviado a diferentes meios de comunicação, a Bombril deu explicações sobre as queixas masculinas registradas no Conselho Nacional de Autorregulamentação Publicitária (CONAR).

Por meio de nota oficial a empresa afirmou que a campanha "foi estrategicamente desenvolvida para valorizar o protagonismo feminino" e que "usa uma linguagem bem-humorada para ressaltar o valor da mulher na sociedade brasileira e não tem a intenção de ofender os homens ao fazer uma brincadeira com a palavra diva" (CONAR, 2015). Não foi possível ter acesso ao texto integral enviado aos veículos de comunicação. Por esse motivo, a análise do posicionamento da Assessoria de Imprensa foi feita observando os trechos supracitados, presentes na nota e publicados por jornais e revistas.

Os fragmentos revelam que com relação às reclamações relacionadas à figura masculina, a Bombril teve um posicionamento justificativo, afir- 
mando que o vídeo "não tem a intenção de ofender os homens" e sim de "valorizar o protagonismo feminino".

No que se refere às acusações de machismo expressas por parte do público, a empresa não se manifestou, potencializando a mensagem da campanha. A propaganda não foi retirada do ar, nem sofreu mudanças.

\section{RISQUÉ}

De origem brasileira, a Risqué já tem mais de cinquenta anos de história. Líder no mercado de esmaltes, em 2010 a marca era responsável por $38,1 \%$ das vendas do produto no Brasil (VENDA, 2011), seguida pelas empresas Colorama e Impala.

Segundo seu site oficial (RISQUÉ, 2015), a Risqué é conhecida por lançar tendências. Anualmente, a marca lança coleções de esmaltes de acordo com as estações, seguindo o padrão primavera-verão e outono-inverno, inspirado na alta moda. A empresa investe também em edições especiais e em uma paleta de cores fixa.

O site da Risqué (www.risque.com.br) não tem informações sobre a história, missão, visão e valores da marca. A empresa tem perfis oficiais nas redes sociais Facebook e Instagram, onde replica fotos enviadas por consumidoras e divulga campanhas publicitárias. Em seu site oficial, redes sociais e nas campanhas que veicula na mídia, a Risqué sempre se refere ao público feminino.

\subsection{HOMENS QUE AMAMOS}

A campanha "Homens que amamos" foi elaborada para divulgar o lançamento da coleção de esmaltes de outono/inverno da marca Risqué. A coleção homônima foi lançada em março de 2015, usando as mídias sociais e o site da empresa como principais veículos de divulgação.

A publicidade da coleção "Homens que amamos" começou com um teaser nas mídias sociais da marca. Conforme demonstra a Figura 2, a identidade visual é a mesma utilizada na publicidade da linha de produtos e o conteúdo instigava a curiosidade das consumidoras. 


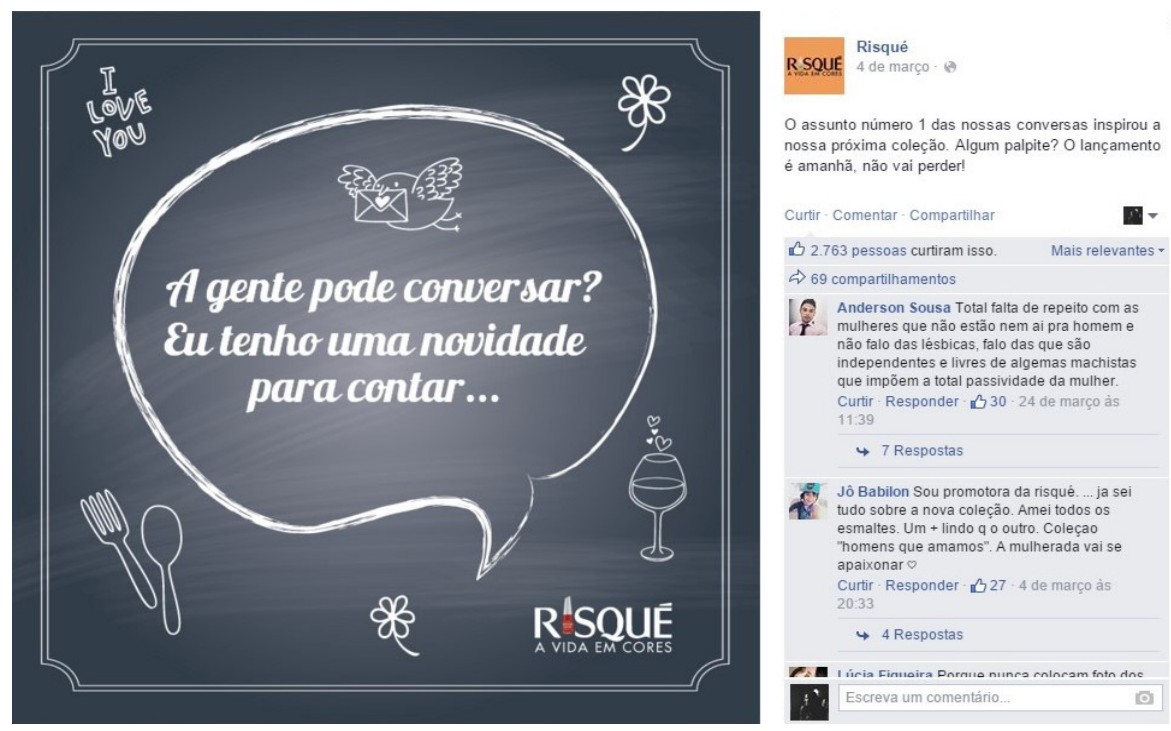

Figura 2 - Prévia da campanha "Homens que amamos"

Fonte: Facebook/Risqué

Na elocução principal, "A gente pode conversar? Eu tenho uma novidade para contar..." a marca se apresenta como uma amiga que chama a consumidora para uma conversa por ter algo importante para anunciar. Na legenda, a empresa se coloca novamente como uma mulher próxima à leitora e dá pistas sobre o tema da próxima coleção. O texto afirma que a linha a ser lançada corresponde ao principal assunto das conversas femininas e questiona se as consumidoras teriam algum palpite.

Já na primeira leitura, elementos como a "novidade", a citação de uma nova coleção e a presença de certo suspense na mensagem, tornam possível afirmar que essa se trata de uma campanha que tem como objetivo a divulgação de um novo produto ou serviço, uma propaganda de lançamento (SANT'ANNA; ROCHA; GARCIA, 2011).

No dia seguinte, a nova coleção foi lançada no site e mídias sociais da Risqué. Composta por seis esmaltes, a linha "Homens que amamos" tem cores denominadas "João disse eu te amo", "Guto fez o pedido", "Zeca chamou para sair", "Fê mandou mensagem”, “André fez o jantar” e "Léo mandou flores".

$\mathrm{Na}$ apresentação da coleção presente no site oficial da marca (Figura 3), a Risqué afirma que o nome dos esmaltes foi inspirado nas atitudes masculinas que agradam as consumidoras e volta a afirmar que homens são um dos assuntos preferidos das mulheres. 


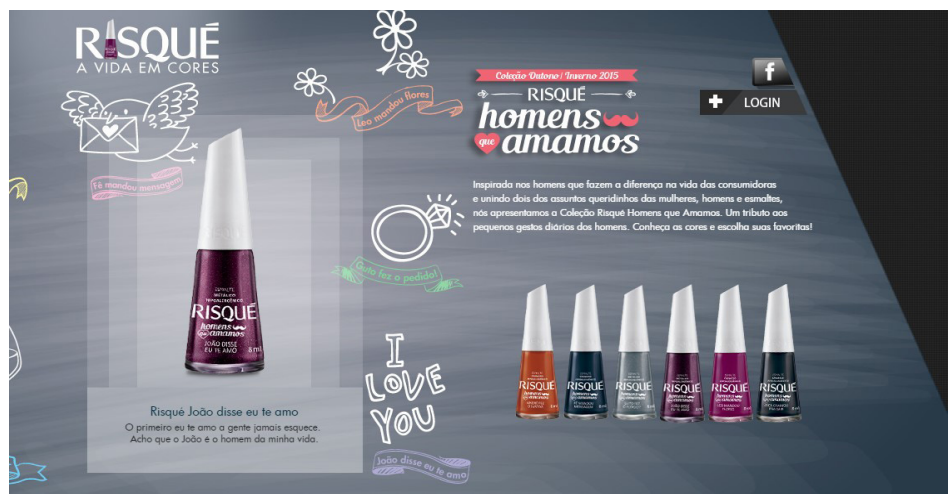

Figura 3 - Campanha "Homens que amamos"

Fonte: Site Oficial/Risqué

Para a mulher imaginada pela publicidade da Risqué, dizer "eu te amo", fazer "o pedido", "mandar mensagem", "chamar para sair" e "mandar flores" seriam atitudes ideais realizadas por um homem em um relacionamento. A propaganda exalta também o ato de "fazer o jantar", quando realizado pelo homem.

No lançamento da linha "Homens que amamos", a marca destaca que as atitudes homenageadas no nome dos esmaltes correspondem a atitudes que fazem diferença da vida das mulheres. Com tal afirmação, a Risqué coloca a consumidora em uma posição dependência, confirmando o estereótipo sexista que afirma que mulheres se realizam a partir da presença masculina em suas vidas. Na frase "unindo dois dos assuntos queridinhos das mulheres, homens e esmaltes", a campanha reforça a visão estereotipada supracitada e afirma mais um estereótipo feminino: mulheres ligam muito para a vaidade e aparência. Além disso, é possível observar que a marca generaliza o pensamento feminino e desconsidera mulheres homossexuais.

Ainda na imagem veiculada no site, a marca afirma que a nova linha de esmaltes é "Um tributo aos pequenos gestos diários dos homens". A frase causa estranhamento pois o público-alvo da Risqué é majoritariamente feminino, mas a marca escolhe homenagear atitudes realizadas por homens ao contrário de, por exemplo, destacar conquistas femininas.

\section{2 "INSPIRADA EM GESTOS DE CARINHO"}

O site Brainstormg (www.bg.com.br), especializado em comunicação digital, procurou a marca questionando sobre a repercussão negativa da campanha supracitada e, em um release dirigido somente ao veículo ci-

Rev.Cad. Comun. Santa Maria, v.21, n.1, art 4, p.98 de 107, jan/abr.2017 
tado, a Assessoria de Imprensa da Risqué respondeu que “A coleção 'Homens que Amamos' foi inspirada em gestos de carinho e respeito vindos de pessoas que amamos. A marca considera todo tipo de discussão positiva e reafirma que está sempre atenta aos comentários de seus consumidores" (LAFLOUFA, 2015).

No release, a marca afirma que a coleção outono/inverno foi criada como uma homenagem a atitudes carinhosas de pessoas amadas. Ao utilizar o termo "pessoas", sem demarcação de gênero, o texto direcionado ao site Brainstormg entra em conflito com relação aos sujeitos responsáveis por inspirar a campanha. Antes "Homens que amamos", agora "pessoas que amamos".

A Assessoria de Imprensa da Risqué utilizou o espaço cedido pelo site para reforçar a imagem da campanha e, ao mesmo tempo, afirmar que a empresa está aberta a questionamentos e atenta à opinião do consumidor. Assim, percebe-se posições antagônicas da Risqué no contexto analisado.

Após repercussão negativa, quase todo conteúdo relacionado à linha "Homens que amamos" publicado nas mídias sócias da Risqué foi apagado. Restaram apenas duas postagens no Facebook da marca. Já no site, o material de campanha continuou disponível até o início da divulgação da coleção de esmaltes primavera/verão 2016. As vendas da coleção analisada continuaram normalmente.

\section{SKOL}

A Skol chegou ao Brasil em 1967 e teve seu percurso de crescimento marcado pela inovação tecnológica. A marca inovou lançando diferentes formatos, embalagens e fórmulas de cerveja, e se diferenciou de outras cervejarias ao investir maciçamente em marketing e no patrocínio de ações esportivas e festivais de música para conquistar o público mais jovem (DIAS, 2006).

Em 2002, a Skol tornou-se, pela primeira vez, a cerveja mais consumida do Brasil, mantendo-se no posto até hoje. Segundo a pesquisa Top of Mind, do Instituto Datafolha, a marca é a primeira a vir à mente do consumidor quando se fala em cerveja (SKOL, 2012).

A Skol é conhecida pelo slogan "A cerveja que desce redondo" e por outros elementos visuais e identitários que se orientam segundo o conceito de "redondo", definido pela marca como o ato de ser feliz, valorizar o 
prazer, estimular a criatividade e a juventude (DIAS, 2006). A proposta é transmitir uma imagem descontraída e jovem, sempre prezando pela inovação e tendo o público de jovens entre 18 e 27 anos como alvo.

$\mathrm{Na}$ internet, a marca utiliza o Facebook, o Instagram, o Twitter e o Youtube para se comunicar com seu público-alvo. O site oficial (www.skol. com.br) compila informações postadas nas redes sociais da empresa, histórico da marca e campanhas veiculadas nas diferentes mídias.

\subsection{ESQUECI O “NÃO" EM CASA}

Veiculada em pontos estratégicos da cidade de São Paulo, a campanha “Esqueci o ‘não' em casa” utilizou o mobiliário urbano da metrópole como espaço de divulgação. A propaganda foi escolhida pela Skol como campanha para o carnaval de 2015 e exposta no início do mês de fevereiro do mesmo ano.

Integrante de uma série de campanhas com o conceito "Viva redondo", a propaganda foi divulgada em conjunto com duas outras peças de mobiliário urbano com as frases "Topo antes de saber qual é a pergunta" e "Tô na sua, mesmo sem saber qual é a sua".

Conforme demonstra a Figura 4, a campanha é apresentada em forma de letreiro. $\mathrm{Na}$ imagem estão presentes o texto central, a frase "Viva redondo", que remete ao slogan da marca, e o botão "ON", símbolo de uma ação promocional promovida pela Skol em parceria com bares do Brasil na época do carnaval. Os elementos correspondem às cores símbolo da empresa, o amarelo e o vermelho.

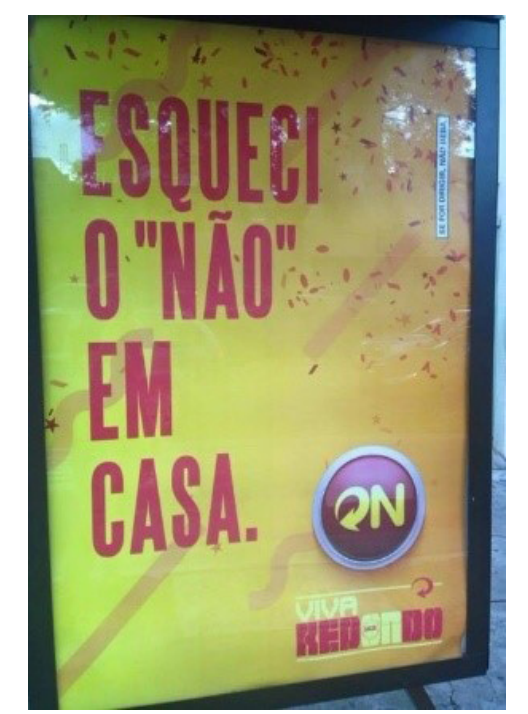

Figura 4 - "Esqueci o 'não' em casa”

Fonte: Imagem de mobiliário urbano em São Paulo, SP

Rev.Cad. Comun. Santa Maria, v.21, n.1, art 4, p.100 de 107, jan/abr.2017 
Na leitura flutuante (FREIRE, 2014), é possível observar que a propaganda não tem como objetivo divulgar lançamentos, pois não anuncia nenhuma novidade, ou promover a marca, já que nem menciona diretamente a Skol. Trata-se de uma campanha de sustentação da empresa, de seus produtos e da ação promocional Skol ON. Esse tipo de publicidade tem como foco manter marca e produto na memória do público-alvo (SANT'ANNA; ROCHA; GARCIA, 2011).

A força da marca Skol é demonstrada pelo apelo visual da propaganda analisada. Em nenhum espaço do mobiliário é indicado o nome da empresa, mas o consumidor observa a identidade gráfica presente no anúncio e fragmentos do slogan expresso na imagem, e facilmente associa esses elementos à fabricante de cervejas.

A frase principal da propaganda "Esqueci o 'não' em casa" simula a fala de um sujeito que teria esquecido as respostas negativas "em casa". Observando o contexto em que a publicidade foi divulgada e analisando os elementos visuais do mobiliário - confetes e serpentinas - é possível perceber que a campanha está relacionada ao carnaval.

Popular pelas comemorações festivas, a época de carnaval também é conhecida pelo consumo excessivo de bebidas alcoólicas e por "envolvimentos amorosos" sem compromisso. A frase da campanha usa o duplo sentido para se referir ao envolvimento sexual durante as festas de carnaval. Ao afirmar que esqueceu o "não" em casa, o sujeito da frase afirma que está aberto a qualquer tipo de relacionamento, ou seja, para ele "vale tudo".

A propaganda pode ser interpretada segundo várias leituras. É possível afirmar que a campanha "Esqueci o 'não' em casa” exalta a liberdade sexual ou que ignora o direito de escolha do indivíduo sobre seu corpo. Levando em consideração o histórico da representação feminina na publicidade de bebidas alcoólicas, pode-se interpretar o texto como uma mensagem sexista que elimina o direito de dizer "não" por parte da mulher ao ser abordada por um homem.

As outras propagandas divulgadas no mobiliário urbano também permitem leituras ambíguas. "Topo antes de saber qual é a pergunta", permite a paráfrase "Não precisa perguntar, afinal, eu já aceitei” e, assim como “Esqueci o 'não' em casa” pode ser interpretada como um estímulo a ignorar o direito de escolha do indivíduo. "Tô na sua, mesmo sem saber qual é a sua" segue o mesmo raciocínio. O sujeito falante na campanha não 
precisa saber quais as intenções da segunda pessoa envolvida no texto, ele aceita qualquer atitude.

\section{2 “RESPEITO À DIVERSIDADE DE OPINIÕES”}

Observando a repercussão negativa da campanha nas redes sociais, a Assessoria de Comunicação da Skol enviou texto a veículos de comunicação online e impressos demonstrando seu posicionamento com relação aos comentários de consumidores.

As peças em questão fazem parte da nossa campanha "Viva Redondo", que tem como mote aceitar os convites da vida e aproveitar os bons momentos. No entanto, fomos alertados nas redes sociais que parte de nossa comunicação poderia resultar em um entendimento dúbio. $\mathrm{E}$, por respeito à diversidade de opiniões, substituiremos as frases atuais por mensagens mais claras e positivas, que transmitam o mesmo conceito. Repudiamos todo e qualquer ato de violência seja física ou emocional e reiteramos o nosso compromisso com o consumo responsável. Agradecemos a todos os comentários (SKOL, 2015).

Em forma de nota oficial (FERRARETTO; FERRARETO, 2009), o texto é iniciado com explicações sobre o objetivo da campanha, que seria celebrar bons momentos e agir de forma positiva frente à vida. A expressão “No entanto", presente na segunda frase, supõe oposição e demonstra que algo não saiu como esperado na execução do projeto. Em seguida, a Assessoria de Comunicação da Skol afirma que a marca foi "alertada" por comentários expressos em mídias sociais que a campanha "Esqueci o 'não' em casa” permitia uma leitura ambígua.

$\mathrm{Na}$ terceira frase do comunicado, a marca anuncia as medidas que serão tomadas após a identificação de reclamações por parte dos consumidores: "por respeito à diversidade de opiniões", a Skol noticia que substituirá as frases atuais por outras mais claras, seguindo o mesmo mote. A Assessoria destaca, ainda, o repúdio da marca por "qualquer ato de violência seja física ou emocional” e afirma que a Skol está comprometida com a questão do consumo responsável. No fim da nota, a marca agradece as reações do público nas redes sociais.

É importante destacar que a empresa agiu com rapidez, se manifestou sobre a polêmica na mesma semana em que a campanha foi divulgada. Também rapidamente as frases nos anúncios foram substituídas por

Rev.Cad. Comun. Santa Maria, v.21, n.1, art 4, p.102 de 107, jan/abr.2017 
outras, conforme demonstrado nas Figuras 5, 6 e 7. No mesmo período, houve a substituição do diretor de marketing da Skol.

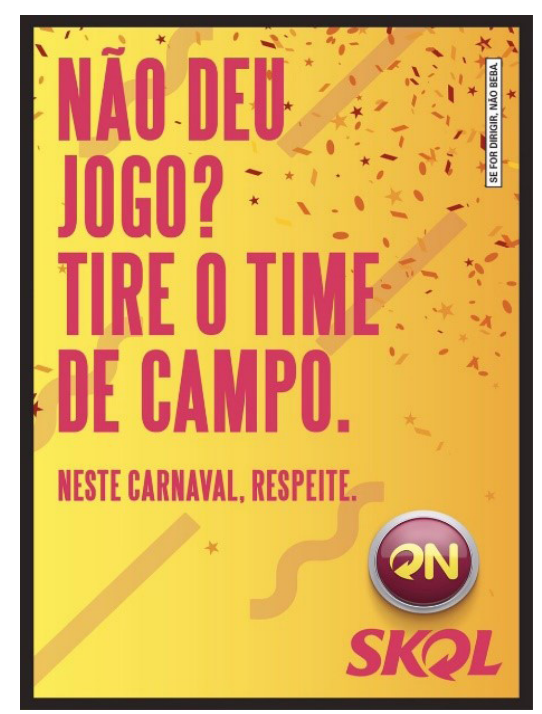

Figura 5 - "Não deu jogo? Tire o time de campo" Fonte: Site Oficial/ Revista Exame

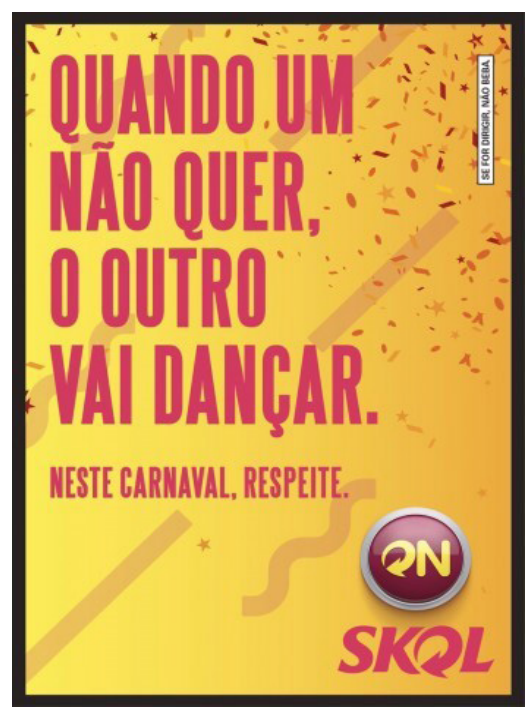

Figura 6 - "Quando um não quer, o outro vai dançar” Fonte: Site Oficial/ Revista Exame

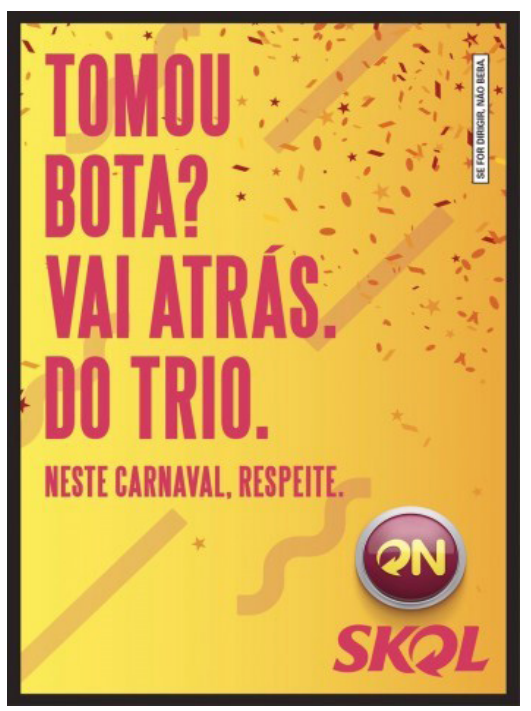

Figura 7 - "Tomou bota? Vai atrás do trio"

Fonte: Site Oficial/ Revista Exame

Os novos textos da campanha ainda falam de relacionamento durante as festas de fevereiro, mas dessa vez pregam o respeito e o direito de escolha. A frase "Neste carnaval, respeite" está presente em todas as peças da campanha. 


\section{CONSIDERAÇÕES FINAIS}

A partir das reflexões presentes neste artigo, foi possível observar que as empresas Bombril, Risqué e Skol adotaram uma linguagem sexista na comunicação de suas campanhas "Toda brasileira é uma diva", "Homens que amamos" e "Esqueci o 'não' em casa”, respectivamente. Apesar de elegerem as mulheres como seu público-alvo, a exceção da Skol, as publicidades dessas marcas não estão alinhadas às demandas feministas da atualidade. Percebe-se também um despreparo das empresas ao lidar com a opinião do público em mídias sociais online. Dentre as marcas analisadas, somente a Skol se posicionou de forma receptiva aos comentários expressos na mídia social, demonstrando abertura também a entender e se alinhar às demandas sociais vigentes.

A pesquisa observou, também, a grande potencialidade de expressão nas mídias sociais, uma vez que a repercussão negativa sobre as peças publicitárias "Esqueci o 'não' em casa”, “Homens que amamos" e "Toda brasileira é uma diva" mobilizou não só usuários das mídias online, atingindo também canais de comunicação online de veículos como o G1 e a Folha de São Paulo. Estes procuraram as empresas analisadas para que expusessem seu posicionamento sobre as opiniões negativas publicadas nas mídias sociais como o Twitter.

Além disso, a realização deste estudo foi importante por representar uma possibilidade de análise crítica e levantamento de questionamentos em relação à responsabilidade social do trabalho de publicidade e das assessorias de comunicação. 


\section{REFERÊNCIAS}

BAUMAN, Zygmunt. Vida para consumo: a transformação das pessoas em mercadorias. Rio de Janeiro: Jorge Zahar Ed, 2008.

BOMBRIL, 2015. Disponível em: <http://www.bombril.com.br>. Acesso em: 26 de outubro de 2015.

CONAR libera propaganda da Bombril acusada de ofender homens. G1. São Paulo, 11 de setembro de 2015. Disponível em: <http://g1.globo.com/economia/midia-e-marketing/noticia/2015/09/conar-libera-propaganda-da-bombril-acusada-de-ofender-homens. html>. Acesso em: 10 de outubro de 2015.

DIAS, Kadu. Bombril. In: DIAS, Kadu. Mundo das marcas. 2006. Disponível em: <http:// mundodasmarcas.blogspot.com.br/2006/05/bombril-1001-utilidades.html>. Acesso em: 2 de outubro de 2015.

DIAS, Kadu. Skol. In: DIAS, Kadu. Mundo das marcas. 2006. Disponível em: <http:// mundodasmarcas.blogspot.com.br/2006/05/bombril-1001-utilidades.html>. Acesso em: 2 de outubro de 2015.

FERRARETTO, Eliza. FERRARETTO, Luiz. Assessoria de imprensa: teoria e prática. São Paulo: Summus, 2009.

FREIRE, Sérgio. Análise do discurso: procedimentos metodológicos [E-book Kindle]. São Paulo: Instituto Census, 2014.

GOMES, Carla; SORJ, Bila. Corpo, geração e identidade: a Marcha das vadias no Brasil. Revista Sociedade e Estado, Brasília, v. 29, n. 2, p. 433-447, aug. 2014. Disponível em:<http://www.scielo.br/scielo.php?script=sci_arttext\&pid=S0102-69922014000200007\&lng=en\&nrm=iso >. Acesso em: $2 \overline{6}$ de outubro 2015.

LAFLOUFA, Jaqueline. Risqué escorrega com coleção com nomes de homens e lida com crise no Twitter \#homensrisque. Brainstorm9. São Paulo, 23 de setembro de 2015. Disponível em: <http://www.b9.com.br/56261/advertising/risque-escorrega-com-colecao-com-nomes-de-homens-e-lida-com-crise-no-twitter-homensrisque/>. Acesso em: 4 de novembro de 2015.

MULHER no mercado de trabalho: perguntas e respostas. Instituto Brasileiro de Geografia e Estatística (IBGE). 2012. Disponível em: <http://www.ibge.gov.br/home/ estatistica/indicadores/trabalhoerendimento/pme_nova/Mulher_Mercado_Trabalho_ Perg_Resp_2012.pdf>. Acesso em: 20 de setembro de 2015.

PEDRO, Joana Maria. O feminismo de "Segunda Onda": Corpo, prazer e trabalho.In: Nova história das mulheres no Brasil. São Paulo: Contexto, 2012. p. 238-259. 
CADERNOS DE COMUNICAÇÃO

UNIVERSIDADE FEDERAL DE SANTA MARIA

RISQUÉ, 2015. Disponível em: <http://www.risque.com.br>. Acesso em: 12 de outubro de 2015 .

SANT'ANNA, Armando; ROCHA, Ismael; GARCIA, Luiz Fernando. Propaganda: teoria, técnica e prática. 8.ed. ver. e ampl. - São Paulo: Thomson Learning, 2011.

SKOL, 2015. Disponível em: <http://www.skol.com.br>. Acesso em: 1 de novembro de 2015.

SKOL e Casas Bahia dividem o topo do ranking em lembrança de marcas em propagandas na TV. Datafolha. São Paulo, 10 de novembro de 2012. Disponível em: <http:// datafolha.folha.uol.com.br/mercado/1265028-bskol-e-casas-bahia-dividem-o-topo-do-ranking-em-lembranca-de-marcas-em-propagandas-na-tvb.shtml>. Acesso em: 17 de outubro de 2015 .

SKOL irá trocar campanha após acusação de 'apologia ao estupro'. G1. São Paulo, 11 de fevereiro de 2015. Disponível em: <http://g1.globo.com/economia/midia-e-marketing/ noticia/2015/02/acusada-de-apologia-ao-estupro-skol-ira-trocar-frases-de-campanha. html>. Acesso em: 10 de novembro de 2015.

SOIBET, Rachel. Movimento de mulheres: a conquista do espaço público. In: Nova história das mulheres no Brasil. São Paulo: Contexto, 2012. p. 218-237.

VENDA de esmalte sobre 23\% e ranking muda. Abras Brasil. 16 de fevereiro de 2011. Disponível em: <http://www.abrasnet.com.br/clipping.php?area=11\&clipping=18621>. Acesso em: 10 de novembro de 2015. 


\section{Laura Máximo Teodoro}

Bacharel em Comunicação Social - Jornalismo pela Universidade Federal de Uberlândia (UFU).

E-mail: lauramaxt@gmail.com

\section{Christiane Pitanga Serafim da Silva}

Doutoranda em Educação, mestre em Comunicação Social pela Universidade Metodista de São Paulo e graduada em Design Gráfico pela Universidade do Estado de Minas Gerais. Professora assistente da Universidade Federal de Uberlândia (curso de Comunicação Social - Jornalismo). E-mail: chrispitanga@yahoo.com.br

RECEBIDO EM: 21/03/2016

ACEITO PARA PUBLICAÇÃO: 20/05/2016 